\title{
P171: Promoting European infection control / hospital hygiene core competencies (EIC/HHCC): a comparative analysis with related disciplines
}

\author{
S Brusaferro ${ }^{1}$, BD Cookson², R Gallagher ${ }^{3}$, P Hartemann ${ }^{4}$, J Holte ${ }^{5}$, S Kalenic ${ }^{6}$, W Popp ${ }^{7}$, GP Privitera ${ }^{8}$, CV Santos ${ }^{9}$, \\ C Suetens $^{9}$, L Arnoldo $^{10}, \mathrm{G}$ Cattani $^{10^{*}}$, E Fabbro $^{11}$
}

From 2nd International Conference on Prevention and Infection Control (ICPIC 2013)

Geneva, Switzerland. 25-28 June 2013

\section{Introduction}

Training Infection Control in Europe (TRICE) in 2010 identified significant differences within European Countries (EC) in the existence of Infection Control /Hospital Hygiene (IC/HH) courses and their compliance with the Improving Patient Safety in Europe (IPSE, 2008) recommended Core Competencies. The need to improve official recognition of "IC/HH degrees" for healthcare professionals also emerged. TRICE further developed, agreed EIC/HHCC with two tiers, published by ECDC in March 2013 as a Technical Document.

\section{Objectives}

Within the ECDC 2012 commissioned project TRICE-IS (Implementation Strategy) we conducted a comparative analysis between EIC/HHCC and IC/HH related disciplines within the broader aim of promoting mutual recognition of courses based on EIC/HHCC within European Countries.

\section{Methods}

We collected documents about disciplines that in TRICE were related to $\mathrm{IC} / \mathrm{HH}$ (Medical Microbiology, Infectious Diseases, Public Health and Epidemiology) and compared them with European IC/HH Core Competencies.

\section{Results}

Documents collected were referred to:Public Health (ASPHER), Epidemiology (ECDC) Public Health Microbiology (EUPHEM, ECDC), Medical Microbiology (UEMS) and Infectious Diseases (UEMS). Global alignment with

\footnotetext{
${ }^{10}$ Publich Health and Prevention Medicine, School of Specialization in Medical Hygiene, University of Udine, Udine, Italy

Full list of author information is available at the end of the article
}

the EIC/HHCC competencies (n.101) resulted: $80 \%$ for ASPHER, 56\% for epidemiology ECDC, 40\% for Infectious Diseases, 20\% Medical Microbiology UEMS and 64,4\% for EUPHEM. In the Program Management area (n. 24 competencies) poor alignment has been identified for Infectious Diseases 37.5\%, and Medical Microbiology (UEMS) 16.7\% and Public Health Microbiology (EUPHEM) 4\%.

\section{Conclusion}

European documents addressing the training of specialties related to $\mathrm{IC} / \mathrm{HH}$ have many topics similar to those reported in the EIC/HHCC. Almost all of them need to be complemented in order to cover the topics mentioned in EIC/HHCC.

\section{Disclosure of interest}

None declared.

\section{Author details}

${ }^{1}$ Medical and Biological Sciences, University of Udine, Udine, Italy. ${ }^{2}$ University College of London, London, UK. ${ }^{3}$ Royal College of Nursing London, London, UK. ${ }^{4}$ Universitè de Lorraine- CHU de Nancy, Nancy, France. ${ }^{5}$ Staten Serum Institute Copenhagen, Copenhagen, Denmark. ' University of Zagreb, Zagreb, Croatia. ${ }^{7}$ University Hospital of Essen, Essen, Germany. ${ }^{8}$ DTRM University of Pisa, Pisa, Italy. ${ }^{9}$ ECDC Stockholm, Stockholm, Sweden. ${ }^{10}$ Publich Health and Prevention Medicine, School of Specialization in Medical Hygiene, University of Udine, Udine, Italy. ${ }^{11}$ Department of Biological and Medical Sciences, University of Udine, Udine, Italy.

Published: 20 June 2013

doi:10.1186/2047-2994-2-S1-P171

Cite this article as: Brusaferro et al:: P171: Promoting European infection control / hospital hygiene core competencies (EIC/HHCC): a

comparative analysis with related disciplines. Antimicrobial Resistance and Infection Control 2013 2(Suppl 1):P171. 